\title{
Human paleobiogeography and the synchrony of social- ecological systems on Earth
}

\author{
Erick Robinson', J.B. Finley ${ }^{1}$, J. Freeman ${ }^{1}$, M. Cannon ${ }^{1}$ and C. Latorre ${ }^{2}$
}

3rd PEOPLE 3000 workshop, Vernal, UT, USA, 20-24 May 2019

The PEOPLE 3000 working group (P3k WG; pastglobalchanges.org/people3000) focuses on integrating archaeological and paleoecological case studies with mathematical modeling. We seek to understand how co-evolving human societies and ecosystems successfully cope with the interrelated forces of population growth, increasing social complexity and climate change, and why some societies subsequently collapse/reorganize. Here we report on the most recent workshop held at Utah State University Vernal (pastglobalchanges.org/calendar/2019/127pages/1909). This workshop challenged participants to consider how integrated paleodata can be used to inform contemporary policy on "climate-smart food systems". We posed the following question to participants: did societies across the world throughout prehistory achieve "triplewins" of increasing economic productivity while reducing anthropogenic impacts on the environment that threaten to decrease the resiliency of societies to environmental change?

This workshop aimed to broaden the geographic scope of the WG and incorporate more early-career researchers (ECRs). We accomplished this goal. ECR attendees specialized in the archaeological and paleoenvironmental data of Central America, Europe, Southwest Asia, Central Asia, and Northern Africa attended the meeting. This enabled us to expand our archaeological radiocarbon dataset to ca. 130,000 dates (Fig. 1). We had a computer scientist attend the meeting in order to facilitate the integrated development of this radiocarbon dataset and overcome the various metadata obstacles to comparative global-scale analyses. This dataset is now the largest archaeological radiocarbon dataset in the world, and overcoming the various metadata obstacles presents unprecedented opportunities for the study of human population ecology. A new collaboration with the LandCover6k project was furthered by the attendance of one of their group leaders at this workshop. Synergies are bound to emerge between these PAGES WGs from the use of the archaeological radiocarbon database as a resource for establishing population growt rates for different regions of the world that in turn can be used to provide baselines for anthropogenic land-use models.

First steps were taken at this workshop to overcome the central challenge of integrating archaeological, paleoclimate, and paleoenvironmental data. This challenge is largely caused by gaps in the spatial and temporal coverage of these different records, and the impacts these gaps have on data resolution and our ability to identify correlations and possible causal processes. In order to overcome these challenges, the P3k WG has developed a new method for modeling human paleodemography according to transient paleoclimate model simulations, rather than modern nationstate boundaries (Robinson et al. 2019). We turned to PaleoView (Fordham et al. 2017) to extract continuous climate model simulation data for every region from which we

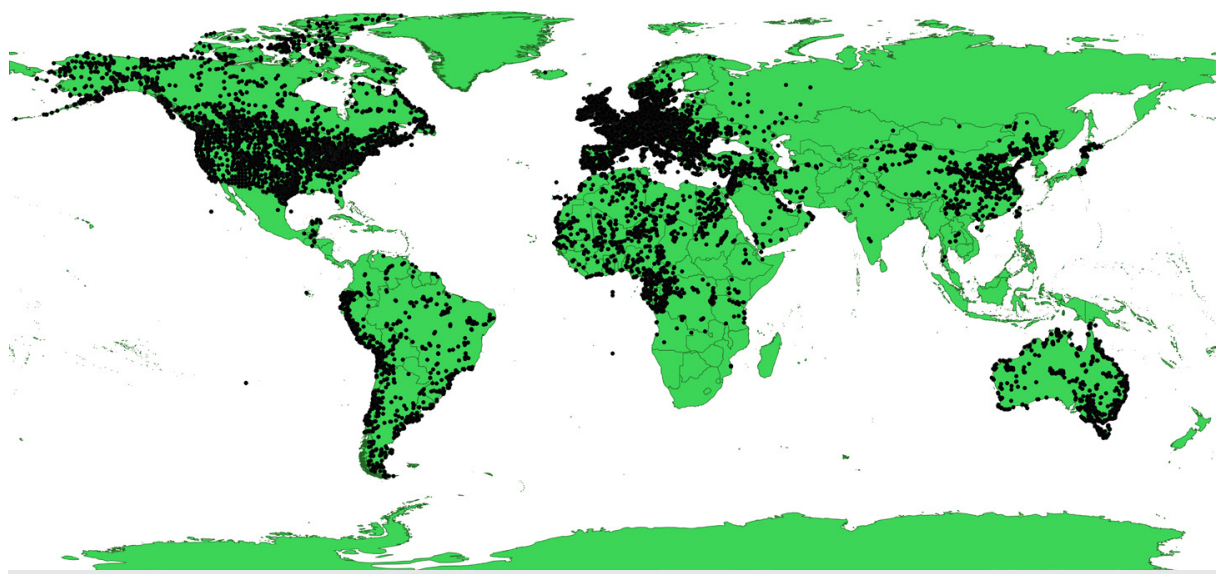

have significant amounts of archaeological radiocarbon data. We then acquired multiproxy paleoenvironmental data for each of these regions in order to start comparing PaleoView to multiple proxy records from different regions. Comparative studies of PaleoView and regional paleoenvironmental records will enable us to identify relevant key ecological parameters for "tipping points" in human social-ecological systems.

The workshop included several public outreach engagements including tours of local archaeological and rodent midden (paleoecological) sites at Dinosaur National Park, a guided tour of the McConkie Ranch rock art panels, and an open house held at the Uintah County Museum. During the open house, scholars from the P3k WG invited members of the public for an evening of conversation about climate-smart food systems. Conversations focused on insights made possible through the interdisciplinary work of archaeologists and paleoecologists from around the world. Together, workshop participants and community members explored strategies, successes, and failures from local contexts and shared perspectives for developing climate-smart food systems for our futures.

P3k WG participants gave in-depth interviews on their research, workshop experience, and collaboration. These interviews will be made available to the public through online podcasts, videos, and Utah Public Radio segments to be aired in early 2020 .

Access the poster highlighting these outreach events at pastglobalchanges.org/ products/pages-outreach/12884

\section{AFFILIATIONS}

Department of Sociology, Social Work, and Anthropology, Utah State University, Logan, USA ${ }^{2}$ Department of Ecology, Pontifical Catholic University of Chile, Santiago, Chile

\section{CONTACT}

Erick Robinson: erick.robinson@usu.edu

REFERENCES

Fordham DA et al. (2017) Ecography 40: 1348-1358 Robinson E et al. (2019) Adv Archaeol Pract 7: 395-408

Figure 1: Locations of all archaeological radiocarbon dates in the PEOPLE 3000 database. 